\title{
Plantas medicinais comercializadas no Mercado Municipal de Campo Grande-MS
}

\section{Mirella Ustulin, ${ }^{1}$ Beatriz de Barros Figueiredo, ${ }^{1}$ Catarine Tremea, ${ }^{1}$ Arnildo Pott, ${ }^{2}$ Vali Joana Pott, ${ }^{2}$ Norlene Regina Bueno, ${ }^{3}$ Rachel Oliveira Castilho ${ }^{*}, 4$}

\author{
${ }^{1}$ Curso de Farmácia, Universidade Católica Dom Bosco, Av. Tamandaré, 6000, Caixa Postal 100, \\ Jardim Seminário, 79117-900 Campo Grande-MS, Brasil \\ ${ }^{2}$ Centro Nacional de Pesquisa e Gado de Corte, BR 262, km 4, CaixaPostal 154, 79002-970 \\ Campo Grande-MS, Brasil \\ ${ }^{3}$ Instituto de Ciências Exatas e Naturais, Universidade Federal do Mato Grosso, Campus Universitário \\ de Rondonópolis, Rodovia Rondonópolis-Guiratinga, km 6, 78735-901 Rondonópolis-MT, Brasil \\ ${ }^{4}$ Faculdade de Farmácia, Departamento de Produtos Farmacêuticos, Universidade Federal de Minas Gerais, Pam- \\ pulha, Avenida Presidente Antônio Carlos, 6627, 31270-901 Belo Horizonte-MG, Brasil
}

\begin{abstract}
RESUMO: O objetivo do presente trabalho foi realizar um levantamento etnofarmacológico das principais espécies vegetais comercializadas no Mercado Municipal de Campo Grande (MS). O estudo foi realizado entre agosto de 2002 e agosto de 2003, através de entrevistas com os raizeiros. Cerca de 117 espécies foram citadas. Foram selecionadas as plantas dos biomas Cerrado e Pantanal e dessas 34 espécies foram adquiridas. Das plantas adquiridas 22 foram identificadas botanicamente, pois o material das outras foi deficiente para determinação até espécie. Das plantas identifificadas, somente dez são típicas do cerrado, podendo-se citar a Curatella americana, Guazuma ulmifolia, Maclura tinctoria e Stryphnodendron obovatum. A família com o maior número de citação foi Asteraceae, seguida de Moraceae, Sterculiaceae e Leguminosae. A parte das plantas mais utilizada é a folha, preparada principalmente como infusão. A indicação terapêutica mais citada foi como cicatrizante, no tratamento de feridas e dores reumáticas. Grande parte das espécies têm indicação de utilização popular para várias patologias e a maioria das espécies $(65,2 \%)$ não teve qualquer estudo farmacológico que confirmasse a indicação popular. Somente oito espécies $(34,8 \%)$ tiveram alguma atividade confirmada na literatura.
\end{abstract}

Unitermos: Plantas medicinais, etnofarmacologia, Campo Grande-MS.

\begin{abstract}
Commercialized medicinal plants in the Mercado Municipal of Campo Grande-MS". The aim of this paper was the survey of the medicinal plants most used from Campo Grande population and commercialized in the Mercado Municipal of Campo Grande, Mato Grosso do Sul, Brazil. The survey was performed in 2002 and 2003 by interviewing and revealed 117 species. Thirty four species were acquired, and of those 22 were identified. Of those ten are only typical of the Cerrado, like as: Curatella americana, Guazuma ulmifolia, Maclura tinctoria, Stryphnodendron obovatum etc. The most mentioned families were Asteraceae, Moraceae, Sterculiaceae and Leguminosae. The most used part of the plant is the leaf, mainly prepared as infusion. These folk-medicine plants have been mostly used for wound healing and the treatment of rheumatism. The species are used for treating diverse pathologies. Data obtained showed that most of the species $(65.2 \%)$ did not have any pharmacological study to confirm the popular indication. Only eight species $(34.8 \%)$ had some activity confirmed in the literature.
\end{abstract}

Keywords: Medicinal plants, ethnopharmacology, Campo Grande-MS.

\section{INTRODUÇÃO}

A utilização de plantas medicinais para tratamento, cura e prevenção de doenças é uma das mais antigas formas de prática medicinal da humanidade. A Organização Mundial de Saúde (OMS), na década de 90, estimou que a maioria da população mundial dependia essencialmente de plantas medicinais para os cuidados básicos de saúde (Akerele, 1992). Ainda hoje nas regiões mais pobres do Brasil e até mesmo nas grandes cidades, plantas medicinais são comercializadas em feiras livres, mercados populares e encontradas em quintais residenciais (Almeida, 1993; Agra et al., 2007 and 2008; Marliére et al., 2008; Veiga-Junior, 2008; Jesus et al., 2009; Leitão et 


\section{al., 2009; Santos et al., 2009).}

A cura de doenças por meio de substâncias biologicamente ativas foi, em sua maior parte, originada de conhecimentos etnofarmacológicos (Elisabetsky, 1991; Albuquerque \& Hanazaki, 2006; Gette et al., 2009). As observações populares sobre o uso de plantas medicinais contribuem de forma relevante para a sugestão de efeitos medicinais e a utilização desses conceitos para estudos farmacológicos e químicos (Maciel et al., 2002; Sousa et al., 2008).

O interesse acadêmico a respeito do conhecimento de plantas medicinais tem crescido, após a constatação de que a base empírica desenvolvida ao longo dos séculos pode em muitos casos ter uma comprovação científica que possibilitaria atender ao binômio segurança e eficácia exigida pelos órgãos de controle de medicamentos (Montanari, 2001; Silveira et al., 2008).

$\mathrm{O}$ estudo das plantas medicinais e seus extratos vegetais são de grande relevância, tendo em vista a utilização das substâncias ativas como protótipos para o desenvolvimento de novos fármacos sintéticos e como fonte de matérias primas farmacêuticas, tanto para a obtenção de fármacos modificados quimicamente (menos tóxicos e mais eficazes), quanto de adjuvantes e fitofármacos (Schulz, 2002; Barbosa-Filho et al., 2007; Saúde-Guimarães \& Faria, 2007; Barbosa-Filho et al., 2008; Corrêa et al., 2008; Quintans-Júnior et al., 2008; Mariath et al., 2009).

Diversas pesquisas sobre a utilização de plantas em tratamentos terapêuticos têm sido realizadas. Entretanto, ainda há muito a se conhecer sobre o uso terapêutico, eficácia e segurança comprovada dos produtos derivados de plantas.

Os objetivos do presente trabalho foram realizar um levantamento etnofarmacológico das principais espécies vegetais indicadas pelos raizeiros que trabalham no Mercado Municipal de Campo Grande-MS e investigar as informações científicas disponíveis sobre essas espécies e compará-las com as informações populares.

\section{MATERIAL E MÉTODOS}

\section{Informações etnobotânicas}

A etapa inicial desse trabalho foi caracterizada pelo levantamento de dados etnofarmacológicos em várias ocasiões entre agosto de 2002 a agosto de 2003, através de entrevistas com todos os raizeiros do Mercado Municipal de Campo Grande-MS, escolhido por ser uma área de grande atividade comercial de raizeiros e de consumidores de seus produtos. As entrevistas foram realizadas com dez raizeiros, segundo um questionário previamente elaborado de acordo com Schardong (1999) e de modo imparcial com o objetivo de dar maior liberdade ao entrevistado. O questionário continha informações como: nome popular da planta, parte utilizada (raiz, caule, folha, casca), forma de utilização (chá, infusão etc.), atividade biológica e sua distribuição.

\section{Identificação botânica do material vegetal}

As plantas medicinais indicadas pelos raizeiros foram adquiridas e encaminhadas para o Herbário de Mato Grosso do Sul (HMS) e para o Centro Nacional de Pesquisa de Gado de Corte (CNPGC-EMBRAPA) e identificadas pelos botânicos Dr. Anildo Pott e Vali Joana Pott.

\section{Levantamento bibliográfico e sistematização de informações populares e científicas}

Posteriormente, realizou-se um levantamento em literatura científica (Portal Capes) das plantas indicadas pelos raizeiros, segundo a identificação botânica, com a finalidade de confirmar e obter informações, tais como: nome científico, família, parte utilizada, origem, área de distribuição, propriedades terapêuticas, constituição química entre outros. Com estas informações foi possível construir uma tabela sobre os dados farmacológicos e etnofarmacológicos de plantas indicadas pelos raizeiros e identificadas pelos botânicos.

\section{RESULTADOS E DISCUSSÃO}

Alguns vendedores coletam as espécies no campo e posteriormente vendem no Mercado Municipal, mas normalmente eles são intermediários que compram as plantas de outras pessoas que realizam a coleta no campo e/ ou que cultivam as plantas e/ou importam. De modo geral, as plantas estavam acondicionadas em sacos plásticos ou amarradas com barbante ou cordas, muitas delas estavam úmidas e contaminadas com insetos e fungos, o que impossibilitou muitas vezes a sua identificação. $\mathrm{O}$ preço médio de cada planta medicinal variou entre R\$ 1,00 e 3,00. Mais de $90 \%$ das plantas medicinais indicadas estavam presentes em todas as bancas.

Foram realizadas entrevistas com todos os raizeiros do Mercado Municipal de Campo Grande (dez raizeiros) e as plantas consideradas nesse trabalho tiveram mais de $50 \%$ de indicações, perfazendo um total de 117 espécies.

Muitas das plantas comercializadas já são muito conhecidas e usadas tradicionalmente e não foram adquiridas para identificação, tais como: sene, maracujá, melissa, hortelã, gengibre, erva-doce, calêndula, boldodo-chile, babosa, alho, alcachofra etc. O uso dessas plantas é consagrado pela população, e muitas delas já foram estudadas cientificamente e constam em literatura especializada (Blumenthal, 1998; Blumenthal et al., 2000; WHO, 2001; Brandão et al., 2006; 2008; 2009) e na RE no 89 de 16 de março de 2004 da Agência Nacional de vigilância Sanitária, na Lista de Registro Simplificado de Fitoterápicos. Priorizou-se, nesse trabalho, a aquisição 
de plantas indicadas originárias dos biomas Pantanal e Cerrado. Um total de 34 plantas medicinais foram adquiridas, e dessas somente 22 foram identificadas botanicamente.

Das 22 plantas identificadas, dez são típicas do cerrado, pode-se citar: Cochlospermum regium, Curatella americana, Dioclea sp., Guazuma ulmifolia, Guazuma tomentosa, Maclura tinctoria, Mikania glomerata, Myracrodruon urundeuva, Phyllanthus corcovandensis, Stryphnodendron oobovatum e Waltheria indica.

Algumas plantas citadas têm nomes populares iguais a de espécies de outras regiões do Brasil, mas foram identificadas como espécies e famílias diferentes. Pode-se citar como exemplo a vassourinha, cujos nomes encontrados na literatura foram Borreria quadrifaria e Borreria verticillata e a espécie vegetal adquirida no Mercado Municipal e identificada foi Lepidium virginicum L. Um outro exemplo é a amora brava, conhecida como Trema micrantha (Rizzini \& Mors, 1995) em outras regiões e identificada como Maclura tinctoria.

Após a identificação e pesquisa bibliográfica, as plantas medicinais foram organizadas em uma tabela (Tabela 1) com os nomes populares citados pelos raizeiros. A maioria das espécies foi citada com os mesmos nomes comuns por todos os raizeiros, indicando que as espécies são geralmente bem conhecidas como remédios tradicionais.

A família com o maior número de citação foi Asteraceae (25\% - Mikania e Baccharis) seguida de Moraceae (Maclura e Morus), Sterculiaceae (Guazuma) e Leguminosae (10\% - Dioclea, Stryphnodendron). Estas famílias representam 47,8\% do total de espécies identificadas. As demais famílias, tais como Anacardiaceae, Dilleniaceae, Cruciferae, Rubiaceae, entre outras, têm apenas uma espécie citada. A parte das plantas mais usada é a folha, sendo preparada principalmente como infusão. Observou-se que treze plantas foram indicadas como cicatrizante, sete plantas são usadas para diarréia e disenteria, seis plantas como diurético, cinco espécies para doenças dos rins e vias urinárias e duas plantas foram indicadas como purgativo e doenças da pele. Para problemas do sistema respiratório três espécies foram indicadas para o tratamento de bronquite, quatro espécies para tosse e duas espécie como anticatarral e para resfriado. A indicação terapêutica mais citada foi como cicatrizante, no tratamento de feridas e dores reumáticas, e as espécies são usadas externamente.

A maioria das espécies (87\%) tem indicação de utilização para várias patologias, como por exemplo, a Curatella americana, utilizada para artrite, diabetes, pressão alta, tosse, bronquite e resfriado e Matricaria chamomila, utilizada para cólicas, como calmante, cicatrizante, etc. Entre as espécies indicadas para diversas enfermidades destacam-se a Matricaria camomila, Baccharis trimera, Guazuma ulmifolia e Heliotropium indicum.

Após a pesquisa bibliográfica e elaboração da Tabela 1, observou-se que onze espécies $(47,8 \%)$ tiveram confirmação de suas indicações etnofarmacológicas na literatura. Quando se comparou os dados etnofarmacológicos com os farmacológicos, verificouse que a maioria das espécies $(65,2 \%)$ não teve qualquer estudo que confirmasse a indicação popular. Somente oito espécies $(34,8 \%)$ tiveram alguma atividade farmacológica confirmada na literatura, pode-se citar: Baccharis trimera (carqueja), com atividade bacteriostática e bactericida, atividade antiinflamatória e analgésica; Cochlospermum regium (algodão): atividade depurativa e efetiva no tratamento de gastrite e úlcera; Curatella americana (lixeira): atividade anti-hipertensiva e vasodilatadora; Equisetum giganteum (cavalinha): atividade diurética; Heliotropium indicum (crista-de-galo): atividade antinflamatória; Matricaria chamomila (camomila): efeito sedativo; Mikania cf. glomerata (guaco): atividade broncodilatadora; Myracrodruon urundeuva (aroeira): atividade cicatrizante, anti-inflamatório e analgésica.

Os resultados obtidos demonstram que as informações dos raizeiros, quanto ao uso terapêutico das plantas citadas como medicinais, coincidem em quase $50 \%$ com as indicações etnofarmacológicas encontradas na literatura, no entanto, somente $34,8 \%$ têm alguma atividade farmacológica comprovada.

As informações etnofarmacológicas oferecem subsídios para estudos fitoquímicos, farmacológicos e de controle de qualidade de plantas medicinais comercializadas e são necessários para avaliação dos seus efeitos farmacológicos e toxicológicos, buscando estratégias seguras para o uso dessas plantas e para a produção de fitoterápicos. Somente assim, as plantas medicinais chegariam aos usuários com comprovação da sua eficácia e ausência de toxidade.

Um outro fator a ser considerado é que a má qualidade das plantas medicinais comercializadas representa um risco em potencial para a população. Essas plantas deveriam ter um controle mais rigoroso, no que diz respeito ao conhecimento de origem das plantas, época da coleta, forma de coleta, armazenamento, secagem, acondicionamento e contaminação por fungos e outros microrganismos. 
Mirella Ustulin, Beatriz de Barros Figueiredo, Catarine Tremea, Arnildo Pott, Vali Joana Pott, Norlene Regina Bueno et al.

Tabela 1. Perfil farmacológico e etnofarmacológico das espécies vegetais comercializadas no Mercado Municipal de Campo Grande (MS).

\begin{tabular}{|c|c|c|c|c|c|c|}
\hline Nome científico & Nome popular & Família & $\begin{array}{l}\text { Órgão e/ou extrato } \\
\text { utilizado e/ou } \\
\text { substância utilizada }\end{array}$ & Ação farmacológica & $\begin{array}{c}\text { Indicações } \\
\text { etnofarmacológicas }\end{array}$ & $\begin{array}{c}\text { Parte } \\
\text { utilizada }\end{array}$ \\
\hline \multirow{3}{*}{$\begin{array}{l}\text { Acanthospermum } \\
\text { australe (Loefl.) } \\
\text { Kuntze }\end{array}$} & \multirow{3}{*}{$\begin{array}{c}\text { Carrapicho, } \\
\text { Carrapicho-praga. }\end{array}$} & \multirow{3}{*}{ Asteraceae } & $\begin{array}{l}\text { Extrato em } \\
\text { diclorometano e } \\
\text { metanólico }\end{array}$ & $\begin{array}{l}\text { Antifúngico (Portillo } \\
\text { et al., 2001) }\end{array}$ & \multirow{3}{*}{$\begin{array}{l}\text { Bronquite e } \\
\text { disenteria }\end{array}$} & \multirow{3}{*}{$\begin{array}{l}\text { Folhas e } \\
\text { raízes }\end{array}$} \\
\hline & & & $\begin{array}{l}\text { Extrato } \\
\text { hidroalcoólico }\end{array}$ & $\begin{array}{l}\text { Antitumoral } \\
\text { (Mirandola et al., } \\
\text { 2002) }\end{array}$ & & \\
\hline & & & Extrato orgânico & $\begin{array}{l}\text { Atividade antimalária } \\
\text { (Carvalho et al., 1991) }\end{array}$ & & \\
\hline \multirow{2}{*}{$\begin{array}{c}\text { Baccharis } \\
\text { dracunculifolia } \\
\text { D.C. }\end{array}$} & \multirow{2}{*}{$\begin{array}{l}\text { Alecrim- } \\
\text { do-campo, } \\
\text { Erva-cidreira-de- } \\
\text { arbusto }\end{array}$} & \multirow{2}{*}{ Asteraceae } & $\begin{array}{l}\text { Exsudato das } \\
\text { folhas }\end{array}$ & $\begin{array}{l}\text { Antifúngico e } \\
\text { antibacteriano } \\
\text { (Bankova et al., 1999) }\end{array}$ & \multirow{2}{*}{$\begin{array}{l}\text { Anti-reumática } \\
\text { anticatarral }\end{array}$} & \multirow{5}{*}{ Folhas } \\
\hline & & & Extrato das folhas & $\begin{array}{l}\text { Inibe } S \text {. mutans (Leitão } \\
\text { et al., 2004) }\end{array}$ & & \\
\hline \multirow{3}{*}{$\begin{array}{l}\text { Baccharis trimera } \\
\text { (Less.) D.C. }\end{array}$} & \multirow{3}{*}{ Carqueja } & \multirow{3}{*}{ Asteraceae } & Extrato butanólico & $\begin{array}{l}\text { Anti-inflamatório e } \\
\text { analgésico } \\
\text { (Gené et al., 1996) }\end{array}$ & \multirow{3}{*}{$\begin{array}{l}\text { Utilizada para } \\
\text { inflamação das } \\
\text { vias urinárias, } \\
\text { diabetes, vermes } \\
\text { intestinais, diurético } \\
\text { e depurativo. } \\
\text { Também dá bons } \\
\text { resultados em } \\
\text { inflamações da } \\
\text { garganta, caso de } \\
\text { gargarejos }\end{array}$} & \\
\hline & & & Decocto da planta & $\begin{array}{l}\text { Bacteriostático e } \\
\text { bactericida } \\
\text { (Avancini et al., 2000) }\end{array}$ & & \\
\hline & & & $\begin{array}{l}\text { Extrato } \\
\text { diclorometano e } \\
\text { metanólico }\end{array}$ & $\begin{array}{l}\text { Efeito vasodilatador } \\
\text { (Hnatyszyn et al., } \\
\text { 2003) }\end{array}$ & & \\
\hline \multirow[b]{2}{*}{$\begin{array}{l}\text { Cochlospermum } \\
\text { regium Pilq. }\end{array}$} & \multirow[b]{2}{*}{ Algodão } & \multirow[b]{2}{*}{ Cochlospermaceae } & $\begin{array}{l}\text { 3-O-glicosil- } \\
\text { dihidrocanferol }\end{array}$ & $\begin{array}{l}\text { Antinociceptivo } \\
\text { (Castro, 2000). }\end{array}$ & \multirow{2}{*}{$\begin{array}{c}\text { Purgativo, } \\
\text { depurativo, usado } \\
\text { para gastrites e } \\
\text { úlceras }\end{array}$} & \\
\hline & & & $\begin{array}{l}\text { Extrato } \\
\text { hidroalcoólico } \\
\text { das partes } \\
\text { subterrâneas }\end{array}$ & $\begin{array}{l}\text { Tóxico (Toledo et al., } \\
\text { 2000) }\end{array}$ & & \\
\hline \multirow{3}{*}{$\begin{array}{c}\text { Curatella } \\
\text { americana } \mathrm{L} .\end{array}$} & \multirow{3}{*}{$\begin{array}{l}\text { Lixeira, caimbé, } \\
\text { cajueiro-bravo, } \\
\text { sambaíba, } \\
\text { marajoara }\end{array}$} & \multirow{3}{*}{ Dilleniaceae } & Extrato etanólico & $\begin{array}{l}\text { Antihipertensivo e } \\
\text { vasodilatador } \\
\text { (Guerrero et al., 2002) }\end{array}$ & \multirow{3}{*}{$\begin{array}{l}\text { Utilizada para } \\
\text { artrite, diabetes e } \\
\text { pressão alta. A flor } \\
\text { é utilizada para } \\
\text { tosse, bronquite e } \\
\text { resfriado }\end{array}$} & \\
\hline & & & $\begin{array}{l}\text { Extrato } \\
\text { hidroalcoólico } \\
\text { da casca }\end{array}$ & $\begin{array}{l}\text { Ant-inflamatório } \\
\text { e analgésico } \\
\text { (Alexandre-Moreira et } \\
\text { al., 1999) }\end{array}$ & & \\
\hline & & & $\begin{array}{l}\text { Extrato } \\
\text { clorofórmico da } \\
\text { casca }\end{array}$ & $\begin{array}{l}\text { Hipoglicemiante e } \\
\text { captador de radicais } \\
\text { livres (Ospina et al., } \\
\text { 1995) }\end{array}$ & & \\
\hline \multirow{2}{*}{$\begin{array}{l}\text { Dioclea } \mathrm{sp} . \\
\text { Spreng }\end{array}$} & \multirow[t]{2}{*}{ Olho-de-boi } & \multirow[t]{2}{*}{ Leguminosae } & $\begin{array}{l}\text { Extrato } \\
\text { hidroalcoólico } \\
\text { de Dioclea } \\
\text { grandiflora }\end{array}$ & $\begin{array}{l}\text { Antinociceptivo } \\
\text { (Almeida et al., 2003). }\end{array}$ & \multirow{2}{*}{$\begin{array}{l}\text { Utilizada para tratar: } \\
\text { febre, doenças da } \\
\text { pele, reumatismo, } \\
\text { disenteria e para } \\
\text { higiene bucal }\end{array}$} & \multirow[t]{2}{*}{ Planta toda } \\
\hline & & & $\begin{array}{l}\text { Diocleina, um } \\
\text { flavonóide de } D . \\
\text { grandiflora }\end{array}$ & $\begin{array}{l}\text { Relaxante da } \\
\text { musculatura lisa } \\
\text { (Lemos et al., 1999) }\end{array}$ & & \\
\hline $\begin{array}{c}\text { Equisetum } \\
\text { giganteum } \mathrm{L} .\end{array}$ & Cavalinha & Equisetaceae & $\begin{array}{l}\text { Extrato } \\
\text { clorofórmico }\end{array}$ & $\begin{array}{l}\text { Diurético (Perez- } \\
\text { Gutierrez, 1985) }\end{array}$ & Infecções renais & \\
\hline \multirow{3}{*}{$\begin{array}{c}\text { Guazuma } \\
\text { ulmifolia Lam. }\end{array}$} & \multirow{3}{*}{ Chico-magro } & \multirow{3}{*}{ Sterculiaceae } & $\begin{array}{l}\text { Extrato aquoso e } \\
\text { metanólico }\end{array}$ & $\begin{array}{l}\text { Antibacteriana } \\
\text { (Camporese et al., } \\
\text { 2003) }\end{array}$ & & \\
\hline & & & $\begin{array}{l}\text { Polímeros de } \\
\text { Proantocianidina }\end{array}$ & $\begin{array}{l}\text { Anti-secretora (Hör et } \\
\text { al., 1996) }\end{array}$ & & \\
\hline & & & $\begin{array}{l}\text { Extrato metanol: } \\
\text { diclorometano da } \\
\text { casca }\end{array}$ & $\begin{array}{l}\text { Inibição angiotensina } \\
\text { II (Caballero-George } \\
\text { et al., 2002) }\end{array}$ & & \\
\hline
\end{tabular}




\begin{tabular}{|c|c|c|c|c|c|c|}
\hline Nome científico & Nome popular & Família & $\begin{array}{l}\text { Órgão e/ou extrato } \\
\text { utilizado e/ou } \\
\text { substância utilizada }\end{array}$ & Ação farmacológica & $\begin{array}{c}\text { Indicações } \\
\text { etnofarmacológicas }\end{array}$ & $\begin{array}{c}\text { Parte } \\
\text { utilizada }\end{array}$ \\
\hline $\begin{array}{c}\text { Guazuma } \\
\text { tomentosa } \mathrm{H} . \mathrm{B} . \\
\text { \& K. }\end{array}$ & Chico-magro & Sterculiaceae & & & $\begin{array}{c}\text { Elefantíase e } \\
\text { doenças da pele e } \\
\text { emagrecimento }\end{array}$ & Casca \\
\hline \multirow{3}{*}{$\begin{array}{l}\text { Heliotropium } \\
\text { indicum } \mathrm{L} .\end{array}$} & \multirow{3}{*}{$\begin{array}{l}\text { Crista-de-galo, } \\
\text { fedegoso-do-mato }\end{array}$} & \multirow{3}{*}{ Boraginaceae } & $\begin{array}{l}\text { Crista-de-galo, } \\
\text { fedegoso-do-mato } \\
\text { Boraginaceae }\end{array}$ & $\begin{array}{l}\text { Anti-inflamatório } \\
\text { (Srinivas et al., 2000) }\end{array}$ & \multirow{3}{*}{$\begin{array}{l}\text { Laxante, diurético, } \\
\text { tosse, hemorróidas, } \\
\text { feridas e úlceras, } \\
\text { queimaduras, } \\
\text { aftas, doenças } \\
\text { respiratórias. }\end{array}$} & \multirow{3}{*}{$\begin{array}{l}\text { Raiz, flor e } \\
\text { folha }\end{array}$} \\
\hline & & & $\begin{array}{l}\text { Alcalóide } \\
\text { pirrolizidínico }\end{array}$ & $\begin{array}{l}\text { Câncer (Ogawa et al., } \\
\text { 1993) }\end{array}$ & & \\
\hline & & & Extrato etanólico & $\begin{array}{l}\text { Cicatrizante (Reddy et } \\
\text { al., 2002) }\end{array}$ & & \\
\hline \multirow{2}{*}{$\begin{array}{c}\text { Lepidium } \\
\text { virginicum } \mathrm{L} .\end{array}$} & \multirow{2}{*}{ Vassourinha } & \multirow{2}{*}{ Brassicaceae } & Glucosinolato & $\begin{array}{l}\text { Inibe Entamoeba } \\
\text { histolytica (Calzada et } \\
\text { al., 2003) }\end{array}$ & \multirow{2}{*}{$\begin{array}{c}\text { Ação emética e para } \\
\text { o tratamento de } \\
\text { feridas }\end{array}$} & \multirow{2}{*}{$\begin{array}{l}\text { Toda a } \\
\text { planta }\end{array}$} \\
\hline & & & $\begin{array}{l}\text { Extratos aquoso, } \\
\text { alcoólico e } \\
\text { cetônico }\end{array}$ & $\begin{array}{l}\text { Citostático (Lopez } \\
\text { Abraham et al., 1979) }\end{array}$ & & \\
\hline \multirow{4}{*}{$\begin{array}{l}\text { Maclura tinctoria } \\
\text { D. Don ex steud. }\end{array}$} & \multirow{4}{*}{ Amora-brava } & \multirow{4}{*}{ Moraceae } & $\begin{array}{l}\text { Extrato etanólico } \\
\text { das folhas }\end{array}$ & $\begin{array}{l}\text { Atividade antifúngica } \\
\text { (ElSohly et al., 2001) }\end{array}$ & \multirow{4}{*}{$\begin{array}{l}\text { Adstringente, } \\
\text { para ferida, sífilis, } \\
\text { reumatismo }\end{array}$} & \\
\hline & & & Chalcona & $\begin{array}{l}\text { Antioxidante (Cioffi } \\
\text { et al., 2003) }\end{array}$ & & \\
\hline & & & Extrato orgânico & $\begin{array}{l}\text { Inibe HIV (Groweiss } \\
\text { et al., 2000) }\end{array}$ & & \\
\hline & & & Extrato etanólico & $\begin{array}{l}\text { Hipoglicemiante } \\
\text { (Petlevski et al., 2001) }\end{array}$ & & \\
\hline \multirow[b]{2}{*}{$\begin{array}{l}\text { Matricaria } \\
\text { recutita } \mathrm{L} \text {. }\end{array}$} & \multirow[b]{2}{*}{ Camomila } & \multirow[b]{2}{*}{ Asteraceae } & $\begin{array}{l}\text { Flores secas } \\
\text { Apigenina e crisina }\end{array}$ & $\begin{array}{l}\text { Sedativo (Avallone, } \\
\text { 2000) }\end{array}$ & \multirow{2}{*}{$\begin{array}{c}\text { Calmante, } \\
\text { antiespasmódica, } \\
\text { febrífuga, } \\
\text { anti-reumática, } \\
\text { antinevrálgica. } \\
\text { É indicada para: } \\
\text { perturbações } \\
\text { gástricas, } \\
\text { diarréia, náuseas, } \\
\text { inflamações das } \\
\text { vias urinárias e } \\
\text { dismenorréia }\end{array}$} & \\
\hline & & & Extrato etanólico & $\begin{array}{l}\text { Hipoglicemiante } \\
\text { (Petlevski et al., 2001) }\end{array}$ & & \\
\hline $\begin{array}{c}\text { Melinis } \\
\text { minutiflora P. } \\
\text { Beauv. }\end{array}$ & Capim-gordura & Gramineae & $\begin{array}{l}\text { Talos verde da } \\
\text { grama }\end{array}$ & $\begin{array}{l}\text { Carrapaticida } \\
\text { (Fernandez- } \\
\text { Ruvalcaba, 2004) } \\
\end{array}$ & $\begin{array}{c}\text { Diurético, } \\
\text { antidisentérico e } \\
\text { antidiarréico }\end{array}$ & \\
\hline \multirow[b]{2}{*}{$\begin{array}{c}\text { Mikania cf. } \\
\text { glomerata Spreng. }\end{array}$} & \multirow[b]{2}{*}{ Guaco } & \multirow[b]{2}{*}{ Asteraceae } & $\begin{array}{l}\text { Extratos aquoso e } \\
\text { hidroalcoólico }\end{array}$ & $\begin{array}{l}\text { Broncodilatador } \\
\text { (Soares de Moura et } \\
\text { al., 2002) }\end{array}$ & \multirow{2}{*}{$\begin{array}{c}\text { Antiasmática, } \\
\text { antigripal, anti- } \\
\text { inflamatória, } \\
\text { anti-reumática, } \\
\text { anti-séptica das } \\
\text { vias respiratórias, } \\
\text { antitussígena, } \\
\text { broncodilatadora, } \\
\text { calmante e } \\
\text { cicatrizante }\end{array}$} & \\
\hline & & & Extrato etanólico & $\begin{array}{l}\text { Anti-inflamatório } \\
\text { (Fierro et al., 1999) }\end{array}$ & & \\
\hline Morus nigra $\mathrm{L}$. & Amora & Moraceae & $\begin{array}{l}\text { Extrato } \\
\text { hidroalcoólico } \\
\text { e polifenólico }\end{array}$ & $\begin{array}{l}\text { Antioxidante (Naderi } \\
\text { et al., 2004) }\end{array}$ & $\begin{array}{l}\text { Anti-inflamatória, } \\
\text { antioxidante, anti- } \\
\text { séptica, calmante, } \\
\text { cicatrizante, } \\
\text { depurativa, } \\
\text { diurética, emoliente } \\
\text { e expectorante }\end{array}$ & \\
\hline
\end{tabular}




\begin{tabular}{|c|c|c|c|c|c|c|}
\hline Nome científico & Nome popular & Família & $\begin{array}{l}\text { Órgão e/ou extrato } \\
\text { utilizado e/ou } \\
\text { substância utilizada }\end{array}$ & Ação farmacológica & $\begin{array}{c}\text { Indicações } \\
\text { etnofarmacológicas }\end{array}$ & $\begin{array}{c}\text { Parte } \\
\text { utilizada }\end{array}$ \\
\hline \multirow{3}{*}{$\begin{array}{c}\text { Myracrodruon } \\
\text { urundeuva Allem. }\end{array}$} & \multirow{3}{*}{$\begin{array}{l}\text { Aroeira, aroeira- } \\
\text { do-sertão }\end{array}$} & \multirow{3}{*}{ Anacardiaceae } & Chalconas & $\begin{array}{l}\text { Anti-inflamatório e } \\
\text { analgésico (Viana et } \\
\text { al., 2003) }\end{array}$ & \multirow{3}{*}{$\begin{array}{c}\text { Tônica, para } \\
\text { hemorragia, } \\
\text { vias respiratória } \\
\text { e urinária, } \\
\text { diarréia, feridas, } \\
\text { antiinflamatório e } \\
\text { cicatrizante, contra } \\
\text { úlceras e alergias }\end{array}$} & \\
\hline & & & Casca do caule & $\begin{array}{l}\text { Úlcera gastroduodenal } \\
\text { e colite (Rodrigues et } \\
\text { al., 2002) }\end{array}$ & & \\
\hline & & & Extrato aquoso & $\begin{array}{l}\text { Cicatrizante (Goes, } \\
\text { 2005) }\end{array}$ & & \\
\hline \multirow{8}{*}{$\begin{array}{c}\text { Ocimum } \\
\text { gratissimum L. }\end{array}$} & \multirow{8}{*}{$\begin{array}{l}\text { Manjericão- } \\
\text { cheiroso, } \\
\text { alfavaca-cravo }\end{array}$} & \multirow{8}{*}{ Labiatae } & $\begin{array}{l}\text { Extrato aquoso das } \\
\text { folhas }\end{array}$ & $\begin{array}{l}\text { Antidiarréico (Offiah, } \\
\text { 1999) }\end{array}$ & \multirow{8}{*}{$\begin{array}{c}\text { Estimulante } \\
\text { carminativo, } \\
\text { sudoríferos, } \\
\text { diuréticos, para } \\
\text { tosse, moléstias } \\
\text { nervosas e } \\
\text { paralisias. Essência } \\
\text { de folhas e flores } \\
\text { é febrífuga e as } \\
\text { sementes são } \\
\text { antiblenorrágicas }\end{array}$} & \\
\hline & & & Extrato de folhas & $\begin{array}{l}\text { Hipoglicemiante } \\
\text { (Aguiyi et al., 2000) }\end{array}$ & & \\
\hline & & & Óleo essencial & $\begin{array}{l}\text { Antinociceptivo } \\
\text { (Rabelo et al., 2003) }\end{array}$ & & \\
\hline & & & Óleo essencial & $\begin{array}{l}\text { Relaxante (Madeira et } \\
\text { al., 2002). }\end{array}$ & & \\
\hline & & & Óleo essencial & $\begin{array}{l}\text { Antibacteriano } \\
\text { (Orafidiya et al., } \\
\text { 2001) }\end{array}$ & & \\
\hline & & & Extratos da planta & $\begin{array}{l}\text { Inibe HIV-1 e HIV-II } \\
\text { (Aysi, 2002) }\end{array}$ & & \\
\hline & & & Óleo essencial & $\begin{array}{l}\text { Antifúngica (Dubey et } \\
\text { al., 2000) }\end{array}$ & & \\
\hline & & & Extrato metanólico & $\begin{array}{l}\text { Ação contra } \\
\text { papilomas (Singh, } \\
1999 \text { ) }\end{array}$ & & \\
\hline $\begin{array}{l}\text { Palicourea } \\
\text { coriacea } \mathrm{K} . \\
\text { Schum. }\end{array}$ & Douradinha & Rubiaceae- & & & $\begin{array}{l}\text { Pedra nos rins, } \\
\text { afecções urinárias, } \\
\text { reumatismos, } \\
\text { distúrbios do ritmo } \\
\text { cardíaco e diurético }\end{array}$ & \\
\hline $\begin{array}{l}\text { Phyllanthus } \\
\text { corcovadensis } \\
\text { Müll Arg. }\end{array}$ & Quebra-pedra & Euphorbiaceae & $\begin{array}{l}\text { Extrato } \\
\text { hidroalcoólico }\end{array}$ & $\begin{array}{l}\text { Antinociceptivo } \\
\text { (Santos et al., 2000) }\end{array}$ & $\begin{array}{c}\text { Diurético e } \\
\text { vermífugo. Contra } \\
\text { cálculo renal e ácido } \\
\text { úrico. Abortiva e } \\
\text { purgativa }\end{array}$ & \\
\hline \multirow{2}{*}{$\begin{array}{l}\text { Stryphnodendron } \\
\text { obovatum Benth. }\end{array}$} & \multirow{2}{*}{ Barbatimão } & \multirow{2}{*}{$\begin{array}{l}\text { Leguminosae- } \\
\text { Mimosoideae }\end{array}$} & $\begin{array}{l}\text { Extrato aquoso da } \\
\text { semente e do caule }\end{array}$ & $\begin{array}{l}\text { Diurético e anti- } \\
\text { diarréico (Silva-Netto, } \\
\text { 1988) }\end{array}$ & \multirow{2}{*}{$\begin{array}{c}\text { Cicatrizante, } \\
\text { hemorragia, } \\
\text { diarréia, frieira, } \\
\text { ferida "braba" de } \\
\text { cavalo, adstringente, } \\
\text { para gengivas e é } \\
\text { abortivo }\end{array}$} & \multirow{2}{*}{$\begin{array}{l}\text { Casca do } \\
\text { caule }\end{array}$} \\
\hline & & & & $\begin{array}{l}\text { Úlcera gástrica } \\
\text { (Favaretto, 1985) }\end{array}$ & & \\
\hline $\begin{array}{c}\text { Waltheria indica } \\
\text { L. }\end{array}$ & $\begin{array}{l}\text { Malva-branca } \\
\text { malva, marva }\end{array}$ & Sterculiaceae & Extratos & $\begin{array}{l}\text { Antimalárico } \\
\text { (Clarkson, 2004) }\end{array}$ & $\begin{array}{c}\text { Disenteria, } \\
\text { sudorífera, ação } \\
\text { emética, diurética, } \\
\text { estimulante e } \\
\text { cicatrizante }\end{array}$ & \\
\hline
\end{tabular}

\section{REFERÊNCIAS}

Agra MF, França PF, Barbosa-Filho JM 2007. Synopsis of the plants known as medicinal and poisonous in Northeast of Brazil. Rev Bras Farmacogn 17: 114-140.

Agra MF, Silva KN, Basílio IJLD, França PF, Barbosa-Filho JM 2008. Survey of medicinal plants used in the region Northeast of Brazil. Rev Bras Farmacogn 18: 472-508. Aguiyi JC, Obi CI, Gang SS, Igweh AC 2000. Hypoglycaemic activity of Ocimum gratissimum in rats. Fitoterapia 71 : 444-446.

Akerele O 1992. Summary of WHO guidelines for the assessment of herbal medicines. Apud: Herbal Gram 28: 13-16, 1990.

Albuquerque UP, Hanazaki N 2006. As pesquisas etnodirigidas na descoberta de novos fármacos de interesse médico e farmacêutico: fragilidades e pespectivas. Rev Bras Farmacogn 16 (Supl.): 678-689. 
Alexandre-Moreira MS, Piuvezam MR, Araújo CC, Thomas G 1999. Studies on the anti-inflammatory and analgesic activity of Curatella americana L. J Ethnopharmacol 67: 171-177.

Almeida ER 1993. Plantas medicinais brasileiras: conhecimentos populares e científicos. São Paulo: Hemus.

Almeida ER, Almeida RN, Navarro DS, Bhattacharryya J, Silva BA, Birnbaum JSP 2003. Central antinociceptive effect of a hydroalcoholic extract of Dioclea grandiflora seeds in rodents. J Ethnopharmacol 88: 1-4.

Avallone R, Zanoli P, Puia G, Kleinschnitz M, Schreier P, Baraldi M 2000. Pharmacological profile of apigenin, a flavonoid isolated from Matricaria chamomilla. Biochem Pharmacol 59: 1387-1394.

Avancini CAM, Wiest JM, Mundstock E 2000. Atividade bacteriostática e bactericida do decocto de Baccharis trimera (Less.) D.C., Asteraceae, Carqueja, como desinfetante ou anti-séptico. Arq Bras Med Vet Zootec 52: $230-234$.

Ayisi NK, Nyadedzor C 2003. Comparative in vitro effects of AZT and extracts of Ocimum gratissimum, Ficus polita, Clausena anisata, Alchornea cordifolia, and Elaeophorbia drupifera against HIV-1 and HIV-2 infections. Antiviral Res 58: 25-33. Referência não citada

Bankova V, Boudourova-Krasteva G, Sforcin JM, Frete X, Kujumgiev A, Maimoni-Rodella R, Popov S 1999. Phytochemical evidence for the plant origin of Brazilian propolis from São Paulo state. Z Naturforsch 54: 401405.

Barbosa-Filho JM, Nascimento-Júnior FA, Tomaz ACA, Athayde-Filho PF, Silva MS, Cunha EVL, Souza MFV, Batista LM, Diniz MFFM 2007. Natural products with antileprotic activity. Rev Bras Farmacogn 17: 141-148.

Barbosa-Filho JM, Alencar AA, Nunes XP, Tomaz ACA, SenaFilho JG, Athayde-Filho PF, Silva MS, Souza MFV, da-Cunha EVL 2008. Sources of alpha-, beta-, gamma-, delta- and epsilon-carotenes: A twentieth century review. Rev Bras Farmacogn 18: 135-154.

Blumenthal M 1998. The complete german commission E monographs - therapeutic guide to herbal medicine. Boston: American Botanical Council.

Blumenthal M, Goldberg A, Brinckmann J 2000. Herbal medicine - expanded commission E monographs. Boston: American Botanical Council.

Brandão MGL, Cosenza GP, Moreira RA, Monte-Mor RLM 2006. Medicinal plants and other botanical products from the Brazilian Official Pharmacopoeia. Rev Bras Farmacogn 16: 408-420.

Brandão MGL, Zanetti NNS, Oliveira GRR, Goulart LO, MonteMor RLM 2008. Other medicinal plants and botanical products from the first edition of the Brazilian Official Pharmacopoeia. Rev Bras Farmacogn 18: 127-134.

Brandão MGL, Cosenza GP, Grael CFF, Monte-Mór RLM 2009. Traditional uses of American plant species from the 1st edition of Brazilian Official Pharmacopoeia. Rev Bras Farmacogn 19: 478-487.

Caballero-George C, Vanderheyden PM, De Bruyne T, Shahat AA, Van Den Heuvel H, Solis PN, Gupta MP, Claeys M, Pieters L, Vauquelin G, Vlietinck AJ 2002. In vitro inhibition of $[3 \mathrm{H}]$-angiotensin II binding on the human AT1 receptor by proanthocyanidins from Guazuma ulmifolia bark. Planta Med 68: 1066-1071.

Calzada F, Barbosa E, Cedillo-Rivera R 2003. Antiamoebic activity of benzyl glucosinolate from Lepidium virginicum. Phytother Res 17: 618-619.

Camporese A, Balick MJ, Arvigo R, Esposito RG, Morsellino N, De Simone F, Tubaro A 2003. Screening of anti-bacterial activity of medicinal plants from Belize (Central America). J Ethnopharmacol 87: 103-107.

Carvalho LH, Brandäo MGL, Santos Filho D, Lopes JLC, Krettli AU 1991. Antimalarial activity of crude extracts from Brazilian plants studied in vivo in Plasmodium berghei infected mice and in vitro against Plasmodium falciparum in culture. Braz J Med Biol Res 24: 1113-1123.

Castro MAS 2000. Mecanismos envolvidos no efeito antinociceptivo do 3-0-glicosil-dihidrocanferol, flavonóide extraído dos rizomas de Cochlospermum regium ("algodãozinho"). São Paulo, 155p. Tese de Doutorado - UNIFESP.

Cioffi G, Morales Escobar L, Braca A, De Tommasi N 2003. Antioxidant chalcone glycosides and flavanones from Maclura (Chlorophora) tinctoria. J Nat Prod 66: 10611064.

Clarkson C, Maharaj VJ, Crouch NR, Grace OM, Pillay P, Matsabisa MG, Bhagwandin N, Smith PJ, Folb PI 2004. In vitro antiplasmodial activity of medicinal plants native to or naturalised in South Africa. J Ethnopharmacol 92: 177-191.

Corrêa MFP, Melo GO, Costa SS 2008. Substâncias de origem vegetal potencialmente úteis na terapia da Asma. Rev Bras Farmacogn 18 (Supl.): 785-797.

Dubey NK, Tiwari TN, Mandin D, Andriamboavonjy H, Chaumont JP 2000. Antifungal properties of Ocimum gratissimum essential oil (ethyl cinnamate chemotype). Fitoterapia 71: 567-569.

Elisabetsky E. 1991. Sociopolitical, economical and ethical issues in medicinal plant research. $J$ Ethnopharmacol 3: 235-239.

ElSohly HN, Joshi AS, Nimrod AC, Walker LA Clark AM 2001. Antifungal chalcones from Maclura tinctoria. Planta Med 67: 87-89.

Favaretto ALV, Contrera MGD, Petenusci SO, Silva Netto C, Lopes RA, Satake T 1985. Açäo cicatrizante do extrato aquoso de casca de Barbatimäo Stryphnodendron obovatum Benth.em úlceras por contençäo em ratos. Rev Esc Farm Odontol 8: 7-12.

Fernandez-Ruvalcaba M, Preciado-De-La Torre F, Cruz-Vazquez C, Garcia-Vazquez Z 2004. Anti-tick effects of Melinis minutiflora and Andropogon gayanus grasses on plots experimentally infested with Boophilus microplus larvae. Exp Appl Acarol 32 293-299.

Fierro IM, Da Silva AC, Lopes CDAS, De Moura RS, BarjaFidalgo C 1999. Studies on the anti-allergic activity of Mikania glomerata. J Ethnopharmacol 66: 19-24.

Gené RM, Cartaña C, Adzet T, Marín E, Parella T, Cañigueral S 1996. Anti-inflammatory and analgesic activity of Baccharis trimera: identification of its active constituents. Planta Med 62: 232-235.

Gette MA, Petenatti ME, Del Vitto LA, Zacchino S, Petenatti EM 2009. Comparative pharmacobotanic study and ethnopharmacological uses of the "Botones de oro" from Argentinean folk medicine. Rev Bras Farmacogn 19: 1419.

Goes ACAM, Rodrigues LV, Menezes DB, Grangeiro MPF, Cavalcante ARMS 2005. Análise histológica da cicatrização da anastomose colônica, em ratos, sob ação 
de enema de aroeira-do-sertão (Myracrodruon urundeuva fr. all.) a 10 por cento. Acta Cir Bras 20: 144-151.

Groweiss A, Cardellina JH, Boyd MR 2000. HIV-Inhibitory prenylated xanthones and flavones from Maclura tinctoria. J Nat Prod 63: 1537-1539.

Guerrero MF, Puebla P, Carrón R, Martín ML, Arteaga L, Román LS 2002. Assessment of the antihypertensive and vasodilator effects of ethanolic extracts of some Colombian medicinal plants. J Ethnopharmacol 80: 3742.

Hör M, Heinrich M, Rimpler H 1996. Proanthocyanidin polymers with antisecretory activity and proanthocyanidin oligomers from Guazuma ulmifolia bark. Phytochemistry 42: 109-119.

Hnatyszyn O, Moscatelli V, Garcia J, Rondina R, Costa M, Arranz C, Balaszczuk A, Ferraro G, Coussio JD 2003. Argentinian plant extracts with relaxant effect on the smooth muscle of the corpus cavernosum of guinea pig. Phytomedicine 10: 669-674.

Jesus NZT, Lima JCS, Silva RM, Espinosa MM, Martins DTO 2009.Levantamentoetnobotânicodeplantaspopularmente utilizadas como antiúlceras e antiinflamatórias pela comunidade de Pirizal, Nossa Senhora do LivramentoMT, Brasil. Rev Bras Farmacogn 19: 130-139.

Leitão DP, Filho AA, Polizello AC, Bastos JK, Spadaro AC 2004. Comparative evaluation of in-vitro effects of Brazilian green propolis and Baccharis dracunculifolia extracts on cariogenic factors of Streptococcus mutans. Biol Pharm Bull 27: 1834-1839.

Leitão F, Fonseca-Kruel VS, Silva IM, Reinert F 2009. Urban ethnobotany in Petrópolis and Nova Friburgo (Rio de Janeiro, Brazil). Rev Bras Farmacogn 19: 333-342.

Lemos VS, Freitas MR, Muller B, Lino YD, Queiroga CEG, Côrtes SF 1999. Dioclein, a new nitric oxide- and endothelium-dependent vasodilator flavonoid. Eur $J$ Pharmacol 386: 41-46.

Lopes GC, Sanches AC, Nakamura CV Dias-Filho BP, Hernandes L. Mello JC 2005. Influence of extracts of Stryphnodendron polyphyllum Mart. and Stryphnodendron obovatum Benth. on the cicatrisation of cutaneous wounds in rats. J Ethnopharmacol 99: 265272.

Lopez Abraham AM, Rojas Hernandez NM, Jimenez Misas CA 1979. Extractos de plantas con propiedades citostáticas que crecen en Cuba. Parte II. Rev Cubana Med Trop 31 : 105-111.

Maciel MAM, Pinto AC, Veiga Júnior VE, Grynberg NF, Echevarria A 2002. Plantas medicinais: a necessidade de estudos multidisciplinares. Quim Nova 25: 429-438.

Madeira SV, Matos FJ, Leal-Cardoso JH, Criddle DN 2002. Relaxant effects of the essential oil of Ocimum gratissimum on isolated ileum of the guinea pig. $J$ Ethnopharmacol 81: 1-4.

Mariath IR, Falcão HS, Barbosa-Filho JM, Sousa LCF, Tomaz ACA, Batista LM, Diniz MFFM, Athayde-Filho PF, Tavares JF, Silva MS, Cunha EVL 2009. Plants of the American continent with antimalarial activity. Rev Bras Farmacogn 19: 158-192.

Marliére LDP, Ribeiro AQ, Brandão MGL, Klein CH, Acurcio FA 2008. Utilização de fitoterápicos por idosos: resultados de um inquérito domiciliar em Belo Horizonte (MG), Brasil. Rev Bras Farmacogn 18 (Supl.): 754-760.

Mirandola L, Justo GZ, Queiroz ML 2002. Modulation by
Acanthospermum australe extracts of the tumor induced hematopoietic changes in mice. Immunopharmacol Immunotoxicol 24: 275-88.

Montanari CA, Bolzani VS 2001. Planejamento racional de fármacos baseado em Produtos Naturais. Quim Nova 24: 105-111.

Naderi GA, Asgary S, Sarraf-Zadegan N, Oroojy H Afshin-Nia F 2004. Antioxidant activity of three extracts of Morus nigra. Phytother Res 18: 365-369.

Offiah VN, Chikwendu UA 1999. Antidiarrhoeal effects of Ocimum gratissimum leaf extract in experimental animals. J Ethnopharmacol 68: 327-330.

Ogawa T, Niwa H, Yamada K 1993. An efficient enantioselective synthesis of indicine $N$-oxide, an antitumor pyrrolizidine alkaloid. Tetrahedron 49: 1571-1578.

Orafidiya LO, Oyedele AO, Shittu AO, Elujoba AA 2001. The formulation of an effective topical antibacterial product containing Ocimum gratissimum leaf essential oil. Int $J$ Pharm 22: 177-183.

Ospina LFG, Olarte JEC, Calle JA, Pinzón RS 1995. Comprobación de la actividad hipoglicemiante y captadora de radicales libres oxigenados de los principios activos de Curatella americana L. Rev Colomb Ciencias Quim Farm 24: 6-11.

Perez-Gutierrez RMF, Laguna GY, Walkowski A 1985.Diuretic activity of Mexican equisetum. J Ethnopharmacol 14: 269-272.

Petlevski R, Hadzija M, Slijepcevic M, Jureti D 2001. Effect of antidiabetis herbal preparation on serum glucose and fructosamine in NOD mice. $J$ Ethnopharmacol 75: 181184.

Portillo A, Vila R, Freixa B, Adzet T, Cañigueral S 2001. Antifungal activity of Paraguayan plants used in traditional medicine. J Ethnopharmacol 76: 93-98.

Quintans-Júnior LJ, Almeida JRGS, Lima JT, Nunes XP, Siqueira JS, Oliveira LEG, Almeida RN, Athayde-Filho PF, Barbosa-Filho JM 2008. Plants with anticonvulsant properties - a review. Rev Bras Farmacogn 18 (Supl.): 798-819.

Rabelo M, Souza EP, Soares PMG, Miranda AV, Matos FJA, Criddle DN 2003. Antinociceptive properties of the essential oil of Ocimum gratissimum L. (Labiatae) in mice. Braz J Med Biol Res 36: 521-524.

Reddy JS, Rao PR, Reddy MS 2002. Wound healing effects of Heliotropium indicum, Plumbago zeylanicum and Acalypha indica in rats. J Ethnopharmacol 79: 249-251.

Rizzini CT, Mors W 1995. Botânica Econômica Brasileira. Rio de Janeiro: Âmbito Cultural.

Rodrigues LV, Ferreira FV, Regadas FS, Matos D, Viana GS 2002. Morphologic and morphometric analyses of acetic acid-induced colitis in rats after treatment with enemas from Myracrodruon urundeuva Fr. All. (Aroeira do Sertão). Phytother Res 16: 267-272.

Santos AR, De Campos RO, Miguel OG, Cechinel-Filho V, Siani AC, Yunes RA, Calixto JB 2000. Antinociceptive properties of extracts of new species of plants of the genus Phyllanthus (Euphorbiaceae). J Ethnopharmacol 72: 229-238.

Santos EB, Dantas GS, Santos HB, Diniz MFFM, Sampaio FC 2009. Estudo etnobotânico de plantas medicinais para problemas bucais no município de João Pessoa, Brasil. Rev Bras Farmacogn 19: 321-324.

Saúde-Guimarães DA, Faria AR 2007. Substâncias da natureza 
com atividade anti-Trypanosoma cruzi. Rev Bras Farmacogn 17: 455-465.

Schardong RMF 1999. Estudos etnobotânicos das plantas de uso medicinal e místico na comunidade de São Benedito, Bairro São Francisco, Campo Grande, MS. Curitiba, 121 p. Dissertação de Mestrado, Curso de Pós-graduação em Botânica, Universidade Federal do Paraná.

Schulz V, Hänsel R, Tyler VE 2002. Fitoterapia Racional. Um guia de fitoterapia para as ciências da saúde. Barueri: Manole.

Silva-Netto CR, Lopes RA, Rossi E, Contrera MGD 1988. Excreção renal de água, sódio e potássio em animais submetidos a sobrecarga aquosa de barbatimão: Stryphodendron obovatum. Pesq Homeopatica 5:9-20.

Silveira PF, Bandeira MAM, Arrais PSD 2008. Farmacovigilância e reações adversas às plantas medicinais e fitoterápicos: uma realidade. Rev Bras Farmacogn 18: 618-626.

Singh A, Singh SP, Bamezai R 1999. Modulatory potential of clocimum oil on mouse skin papillomagenesis and the xenobiotic detoxication system. Food Chem Toxicol 37: 663-670.

Soares de Moura R, Costa SS, Jansen JM, Silva CA, Lopes CS, Bernardo-Filho M, Nascimento da Silva V, Criddle DN, Portela BN, Rubenich LM, Araujo RG, Carvalho LC 2002. Bronchodilator activity of Mikania glomerata Sprengel on human bronchi and guinea-pig trachea. $J$ Pharm Pharmacol 54: 249-256.

Sousa FCF, Melo CTV, Citó MCO, Félix FHC, Vasconcelos SMM, Fonteles MMF, Barbosa-Filho JM, Viana GSB 2008. Plantas medicinais e seus constituintes bioativos: Uma revisão da bioatividade e potenciais benefícios nos distúrbios da ansiedade em modelos animais. Rev Bras Farmacogn 18: 642-654.

Srinivas K, Rao MEB, Rao SS 2000. Anti-inflammatory activity of Heliotropium indicum linn. and Leucas aspera Spreng. in albino rats. Indian J Pharmacol 32: 37-38.

Toledo M, Siqueira JM, Araújo L, Oga S 2000. Acute and subacute toxicity of Cochlospermum regium (Mart. \& Schr.) pilger. Phytother Res 4: 359-361.

Veiga-Junior VF 2008. Estudo do consumo de plantas medicinais na Região Centro-Norte do Estado do Rio de Janeiro: aceitação pelos profissionais de saúde e modo de uso pela população. Rev Bras Farmacogn 18: 308-313.

Viana GS, Bandeira MA, Matos FJ 2003. Analgesic and antiinflammatory effects of chalcones isolated from Myracrodruon urundeuva Allemão. Phytomedicine 10: 189-195.

WHO 2001. WHO monographs on selected medicinal plants. Genebra: World Health Organization. 